\title{
CONTROLE ALTERNATIVO DE INSETOS DE IMPORTANCIA AGRÍCOLA COM USO DE EXTRATOS VEGETAIS DE LIPPIA INSIGNIS E LIPPIA THYMOIDES, EM FEIRA DE SANTANA, BAHIA, BRASIL
}

\section{$\underline{\text { Mainã Medeiros Oliveira }}{ }^{1}$; Jucelho Dantas da $\mathrm{Cruz}^{2}$; Daiane Rodrigues dos $\operatorname{Santos}^{3}$ e Iara Liandra Santana Silva ${ }^{4}$}

\author{
1. Bolsista PIBIC/CNPq, Graduando em Agronomia, Universidade Estadual de Feira de Santana, e-mail: \\ maina_medeiros@hotmail.com \\ 2. Orientador, Departamento de Ciências Biológicas, Universidade Estadual de Feira de Santana, e-mail: \\ jucelho@ig.com.br \\ 3. Participante do projeto, Departamento de Ciências Biológicas, Universidade Estadual de Feira de Santana, e-mail: \\ daibio@ hotmail.com.br \\ 4. Participante do projeto, Departamento de Nome, Universidade Estadual de Feira de Santana, e-mail: \\ yara_lian@hotmail.com
}

PALAVRAS-CHAVE: Verbanaceae; Callosobruchus maculatus; Biopesticidas.

\section{INTRODUÇÃO}

O semiárido nordestino desponta como um dos ecossistemas mais valiosos, apresentando em seu domínio um número expressivo de espécies de plantas e microorganismos com elevados potenciais para produção de substâncias bioativas passíveis de aplicação como alimentos, em produtos farmacêuticos e na agricultura (Queiroz et al., 2006). Dentre essas plantas destacam-se as do gênero Lippia, devido ao grande uso de óleos medicinais, com ampla utilização nas indústrias e por possuírem propriedades inseticidas (Jannuzzi, 2010; Silva, 2012).

Com a Revolução de 1930 houve um aumento da população mundial demandando aumento da produção de alimentos e isso culminou no aparecimento das monoculturas. Essa prática favoreceu o desenvolvimento do que chamamos de insetos-pragas, que vem causando prejuízo à cadeia de produção com o gasto com agroquímicos. Dentre as pragas de maior importância e que tem causado enormes impactos econômicos têm-se o caruncho (Callosobruchus maculatus), inseto-praga que ataca principalmente a cultura do feijão tanto em campo como em estádio de armazenamento.

Devido ao uso indiscriminado das substâncias químicas inseticidas e os impactos naturais por elas causados, tem-se surgido o interesse pela utilização de inseticidas botânicos. Apesar de existir uma grande variedade de plantas com potencial inseticida comprovado pelo uso popular, torna-se necessário estudo voltado para a caracterização e potencial biológico desses produtos.

Desse modo, e a cada dia crescente o número de estudos voltados para a utilização do potencial bioativo e da caracterização desses produtos oriundos de planta no combate a insetos pragas, esse trabalho visou avaliar a atividade inseticida e repelente com extratos e óleos das espécies Lippia insignis (Molden,1976) e L. thymoides (Martius \& Schauer, 1847) no combate à C. maculatus .

\section{METODOLOGIA}

Coleta das espécies vegetais e insetos utilizados

As plantas utilizadas para obtenção dos extratos e óleo essencial foram coletadas na coleção de plantas medicinais e aromáticas da Unidade Experimental Horto Florestal da 
Universidade Estadual de Feira de Santana (UEFS). Os insetos utilizados foram coletados no centro de abastecimento da cidade de Feira de Santana, levados a laboratório e acondicionados em potes plásticos. Constantemente realizou-se troca dos insetos nos potes propiciando a manutenção das gerações durante o experimento.

\section{Obtenção dos extratos e óleos essenciais}

Para obtenção do extrato aquoso secou-se as folhas, passou no moinho de facas, misturando o pó obtido à água destilada na proporção de $10 \mathrm{~g}$ do pó em $100 \mathrm{ml}$ de água, chegando a uma concentração de $10 \%(\mathrm{P} / \mathrm{V})$. Posteriormente, as suspensões foram filtradas em um tecido fino (voil), resultando na obtenção dos extratos aquosos. Para extração do óleo, o método utilizado foi o de arraste a vapor, por aparelho de destilação tipo Clevenger.

\section{Avaliação in vitro do extrato aquoso}

Foi realizada analise in vitro do potencial inseticida do extrato aquoso (10\%) das espécies Lippia insignis e Lippia thymoide. Utilizou-se o método da exposição à superfície contaminada, 10 insetos de curculionidaes em cada placa de petri embebida com 1,5 ml do extrato aquoso das espécies analisadas. O comportamento dos insetos foi avaliado durante, 24 e 48 horas após a aplicação dos tratamentos. $\mathrm{O}$ experimento foi inteiramente casualisado com 4 tratamentos, de 4 repetições.

Avaliação do óleo de $L$. insignis através de dois métodos de aplicação (Adapt. Santos et al , 2013)

Foi realizada avaliação de mortalidade do óleo de Lippia insignes na concentração $\left(5 \mu 1 / \mathrm{ml}^{-1}\right.$ ) contra $C$. maculatus em dois diferentes métodos de aplicação tópica e superfície contaminada. Para o teste de aplicação tópica os insetos foram borrifados com 1,5 ml da solução do óleo essencial, como controle foi utilizado solução de tween $1 \%$, e em exposição por superfície contaminada, embebeu o papel filtro com 1,5 $\mathrm{ml}$ da mesma solução e colocou os insetos sobre ele. Ambos os métodos tiveram 10 repetições em delineamento inteiramente casualizado.

\section{RESULTADOS E/OU DISCUSSÃO (ou Análise e discussão dos resultados)}

\section{Extrato aquoso}

Avaliando a ação inseticida do extrato aquoso de Lippia insignis e L. thymoides, de um modo geral, houve diferenças estatísticas significativas dos tratamentos com relação ao controle, sobretudo de L. insignis, demonstrando o potencial inseticida do extrato aquoso (10\%) das espécies analisadas contra C. maculatus. De acordo com os resultados demonstrados no Gráfico 1, as mortalidades observadas foi de 15\% no controle (água destilada), $27 \%$ para $L$. thymoides e $41,25 \%$ para $L$. insignis, ficando constatado que a espécie $L$. insignis quanto a aplicação do extrato aquoso contra $C$. maculatus obteve maior potencial inseticida portanto é a espécie mais recomendada para uso. Almeida et al. (2004) também encontrou sucesso utilizado extrato aquoso contra $C$. maculatus, sendo que os mesmos constataram que a maior mortalidade de insetos ocorreu com período maior de exposição aos extratos. 


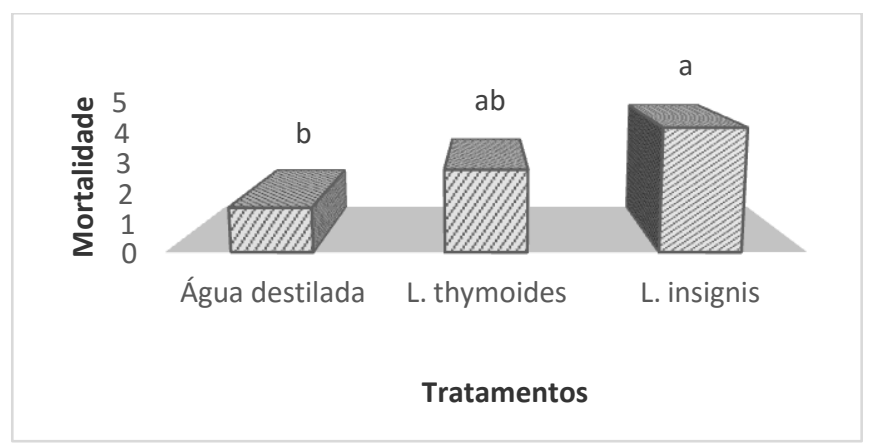

Gráfico 1. Médias de mortalidade de C. maculatus por tratamento submetidos a exposição à superfície contaminada com extrato aquoso (10\%) de espécies do gênero Lippia.

\section{Avaliação da eficiência de dois diferentes métodos de aplicação:}

Foi observado de acordo com a comparação dos métodos de aplicação da dose letal de $50 \%\left(5 \mu \mathrm{l} / \mathrm{ml}^{-1}\right)$ contra $C$. maculatus que o método da aplicação tópica, dados apresentados na Tabela 2, apresentou mortalidade gerais igual a 55\%, diferindo significativamente do controle. Apesar do controle ter demonstrado uma mortalidade maior com 48 horas, o tratamento apresenta uma alta taxa de mortalidade inicial, concluindo assim que há uma eficiência imediata do produto com relação a resposta do controle.Quando analisando a exposição dos insetos à superfície contaminada percebe-se também, que houve uma diferença estatística significativa nas médias gerais de mortalidade. Observando o fator tempo, percebe-se diferenças significativas tanto no controle como no tratamento, no entanto, no tratamento o último período avaliado apresentou mais que o dobro de mortalidade do controle, apresentando sempre mortalidade maiores quando comparada com a testemunha.

\begin{tabular}{|c|c|c|c|}
\hline \multirow[t]{2}{*}{ MÉTODO } & \multicolumn{2}{|c|}{ MORTALIDADE (\%) } & \multirow[t]{2}{*}{ MÉDIAS (\%) } \\
\hline & $24 \mathrm{hs}$ & $48 \mathrm{hs}$ & \\
\hline ADE + TWEEN $20(1 \%)$ & $0,80 \mathrm{~b} \mathrm{~A}$ & $28,00 \mathrm{~b} \mathrm{~B}$ & $18,00 \mathrm{~b}$ \\
\hline APLICAÇÃO TÓPICA & 48,00 a $\mathrm{A}$ & 62,00 a A & $55,00 \mathrm{a}$ \\
\hline CV\% & 20,16 & & \\
\hline $\operatorname{ADE}^{-\operatorname{TWEEN}_{20}(1 \%)}$ & $16,00 \mathrm{aA}$ & $30,00 \mathrm{aA}$ & $23,00 \mathrm{~b}$ \\
\hline $\begin{array}{l}\text { SUPERFICIE } \\
\text { CONTAMINADA }\end{array}$ & $30,00 \mathrm{aA}$ & $62,50 \mathrm{aB}$ & $46,25 \mathrm{a}$ \\
\hline CV\% & 22,75 & & \\
\hline
\end{tabular}

TABELA 2. Avaliação da ação da $\operatorname{DL} 50\left(5 \mu 1 / \mathrm{ml}^{-1}\right)$ sobre $C$. maculatus, através do método de aplicação tópica e superfície contaminada em 24 e 48 horas.

\footnotetext{
* Médias seguidas de mesma letra maiúscula na linha não diferem entre si pelo teste de Tukey a 5\% de probabilidade. Médias seguidas pela mesma letra minúscula na coluna não diferem entre si pelo teste de tukey a $5 \%$ de probabilidade. Mortalidade obtida através da raiz quadrada de $\mathrm{y}+1.0$ - sqrt $(\mathrm{y}+1.0)$.
}

Comparando os dois tratamentos, podemos avaliar que o uso da aplicação tópica mostrou-se nos experimentos in vitro contra $C$. maculatus mais eficiente com relação a 
superfície contaminada, demonstrado pela média de mortalidade superior, $55 \%$ contra 46,25\%. Santos et al, (2010) realizando trabalho com aplicação tópica e superfície contaminada observou resultados diferente, sendo que, a aplicação em superfície contaminada foi mais eficiente que a aplicação tópica. Porém a aplicação tópica pode ser interessante devido a falta de efeito residual como ocorre na superfície contaminada, que pode ser vantajoso em se tratando de um produto armazenado.

\section{CONSIDERAÇÕES FINAIS}

Através dos resultados obtidos nos diferentes experimentos pode-se concluir que a Lippia insignis é a espécie que se destacou em mortalidade e repelência contra $C$. maculatus quando comparada a $L$. thymoides sendo, portanto recomendada aplicação em campo.

Em comparação aos testes de aplicação tópica e superfície contaminada, o segundo foi mais eficiente, destacando-se no nível de mortalidade.

\section{REFERÊNCIAS}

ALMEIDA, Silvana A. de; ALMEIDA, Francisco de A. C. 2; SANTOS, Nilene R. dos 1; ARAÚJO, Maria E. R.; RODRIGUES, Joaquim P. ATIVIDADE INSETICIDA DE EXTRATOS VEGETAIS SOBRE Callosobruchus maculatus (Fabr., 1775) (COLEOPTERA: BRUCHIDAE) R. bras. Agrociência, v. 10, n. 1, p. 67-70, 2004.

JANNUZZI H; MATTOS JKA; VIEIRA RF; SILVA DB; BIZZO HR; GRACINDO LAM. 2010. Avaliação agronômica e identificação de quimiotipos de erva cidreira no Distrito Federal. Horticultura Brasileira 28: 412-417, 2010.

QUEIROZ, L. P.; RAPINI, A.; GIUlIETTI, A. M. Rumo ao Amplo Conhecimento da Biodiversidade do Semi-árido Brasileiro. Brasília: Ministério da Ciência e Tecnologia, 2006.

SANTOS, M. R. A. dos; SILVA, A. G.; LIMA, R. A.; LIMA, D. K. S.; SALLET, L. A. P.; TEIXEIRA, C. A. D.; POLLI, A. R.; FACUNDO, V. A.; Atividade inseticida do extrato das folhas de Piper hispidum (Piperaceae) sobre a broca-do-café (Hypothenemus hampei). Revista Brasil. Bot., V.33, n.2, p.319-324, 2010.

SANTOS, M.R.A.; LIMA, R.A.; SILVA, A.G.; LIMA, D.K.S.; SALLET, L.A.P.; TEIXEIRA, C.A.D.; FACUNDO, V.A.; Composição química e atividade inseticida do óleo essencial de Schinus terebinthifolius Raddi (Anacardiaceae) sobre a broca-docafé (Hypothenemus hampei) Ferrari Rev. Bras. Pl. Med., Campinas, v.15, n.4, supl.I, p.757-762, 2013.

SILVA, F. S.; ESTUDO FITOQUÍMICO E FARMACOLÓGICO DE Lippia thymoides MART. \& SCHAUER (VERBENACEAE). Universidade Estadual de Feira de Santana, 2012. 